\title{
Markets for Freshwater Ecosystem Services
}

\author{
Martin W Doyle ${ }^{1}$ and Todd BenDor ${ }^{2}$ \\ ${ }^{1}$ Department of Geography and Institute for the Environment \\ ${ }^{2}$ Department of City and Regional Planning \\ University of North Carolina, Chapel Hill
}

\section{Introduction}

Humans have altered freshwater ecosystems worldwide. With the dramatic increase in irrigation, water storage projects, and land utilization through the 20th century, the scale of environmental conversion has grown to influence fundamental biophysical processes including fundamental changes to the water cycle, cycling of elements (e.g., carbon, nitrogen, phosphorus), species composition, and climate (Vitousek et al., 1997). These transformations have raised urgent questions about the possibility of conserving and possibly restoring damaged freshwater ecosystems. While environmental conservation and restoration efforts have historically focused on recovering important organisms (flora and fauna), recent scientific and policy endeavors have centered on sustaining the services produced by ecosystems and their components. One way of accomplishing this is through of the creation and use of ecosystem service markets.

Ecosystems are often defined as the complex of 1) organisms appearing together in a given area and 2) their associated abiotic environment, which interact through energy fluxes in order to construct biotic structures and material cycles (Millennium Ecosystem Assessment [MEA], 2005; note all abbreviations provided at end of paper). The study of ecosystems is somewhat distinct from that of the field of ecology in that ecosystem ecologists generally study material or energy fluxes, while other ecologists commonly focus on the behavior or patterns of particular organisms or groups of organisms. Additionally, ecosystem ecologists generally consider ecosystems to be landscape features (physical features in the natural environment) that have the ability to produce various functions. Here, ecosystem functions are the ability of a particular ecosystem (i.e., area) to change the flux or storage of material or energy through time. These functions include photosynthesis, nutrient uptake or retention, metabolism, or any other 
process characterized by the entirety of the ecosystem feature (physical expression of ecosystem) rather than the process of any particular individual organism or species.

"Ecosystem services" are derived from the beneficial outcomes of ecosystem functions. These services provide the benefits that produce ecological value (Daily et al., 1997; King and Herbert 1997). For example, streams and wetland naturally function as retainers of nitrogen; in watersheds in which there are nitrogen-driven water quality problems (e.g., hypoxia of estuaries), nitrogen retention would be considered valuable ecosystem service. The Millennium Ecosystem Assessment (MEA, 2005) groups ecosystem services into four categories: provisioning services (e.g. providing food and water); regulating services (e.g. disease regulation); cultural services (e.g. recreation opportunities); and supporting services (services necessary for the production of other service types). The lists of potential ecosystem services appear to increase with time, and Ruhl et al. (2007) provide a useful review and synthesis.

Markets for these services are as difficult to define as functions and services themselves. Perhaps the most reasonable definition is given by Robertson (2006), who defines ecosystem service markets as those that trade commodities based on ecological assessment criteria, such as wetlands, rather than units of weight or volume, such as the case for the acid rain program. However, the clarity of this definition begins to break down as ecosystem service markets begin to interact with more tradition environmental markets, as in the case when there are both wetland and water quality markets. As we will discuss in this chapter, there are instances in which markets attempt to trade in weight or volume units whose values are estimated using ecological assessment criteria (we describe this using the example of point-source to non-point-source water quality trading). Given these complicating factors, it is imperative in any discussion of ecosystem markets to understand a range of different resource markets and trading structures. Substantial differences in commodity units and methods of assessment introduce problems that confront researchers and practitioners who study and implement different types of markets.

In this chapter, we focus on freshwater ecosystem markets that currently exist, as opposed to the many that are conceptual or have merely been proposed. Wetlands and streams comprise the oldest ecosystem markets, and continue to be the most active at the national scale. In discussing wetlands and streams, we will focus our discussion and examples on markets in North Carolina since they have been active for over a decade, and have been the focus of several recent studies as well as recent federal and state regulation revisions. Although the experience 
of designing and implementing these markets meant successfully navigating certain policy and scientific problems, many others have been exposed and are still in need of further study and remedy. In addition to freshwater ecosystem markets, we also look at habitat conservation banking, an emerging market that presents a new set of opportunities and challenges that will likely interact with these existing markets in the future. We will describe the policies that created these markets, including those crafted the federal, state, and local level. We will also present a series of summary statistics that provide a sense of scale of these markets. Finally, we use these examples to point toward some of the potential limitations or problems of these markets that merit considerable thought and research attention as comparable markets are developed.

\section{Ecosystem Service Markets: Description and Regulation}

\subsection{The Origin of Wetland Markets}

Ecosystem service markets are almost all in some way based on or similar to wetland markets. Wetland regulation in the United States is rooted in the U.S. Federal Water Pollution Control Act of 1972, and the Clean Water Act of 1977, which provides for the protection of "waters of the U.S." under the interstate commerce clause of the U.S. Constitution. Congress designated the Army Corps of Engineers (hereafter "Corps") to administer Section 404 for waters of the U.S. with oversight from the U.S. Environmental Protection Agency (EPA). Through judicial interpretation "waters of the United States" includes navigable waterways, small streams and tributaries, and wetlands (Downing et al., 2003). Most development activities that affect waters of the U.S. fall under Section 404 of the Clean Water Act, and thus require a permit from the Corps. As part of the 404 program, the permittee must mitigate wetland damage, a process through which they (a) avoid all possible impacts, (b) minimize unavoidable impacts, and (c) provide compensatory mitigation of unavoidable impacts, i.e., create, restore, or preserve wetlands such that there is no net loss of cumulative wetland ecosystem function (see Hough and Robertson, in press, for historical overview of U.S. wetland mitigation regulations). .

In the early years of this regulation (until the mid-1990s), compensatory mitigation was usually performed on-site by the permittee (also often called the 'developer' or 'impactor'), resulting in the creation or restoration of numerous, small mitigation sites with limited ecological 
value in comparison to existing, less disturbed wetlands. During this period, regulations also began promoting off-site compensatory mitigation by permittees. Although this was thought to promote better mitigation, the ecological values of these compensation sites were often extremely low, and the permittee, often a private land developer or a state department of transportation, did not want to be in the business of ecological restoration.

In response to slow Section 404 permitting, due to the high volume of compensation sites that had to be approved by the Corps, and high permittee-responsible mitigation costs throughout the early-1990s, entrepreneurs and regulators proposed creating large, consolidated areas of constructed wetlands, known as 'mitigation banks,' as pre-impact or advance compensation (Robertson, 2006). In conjunction with the entrepreneurial mitigation bankers, developers, and EPA staff, Corps districts developed the regulatory guidance necessary to define, create and maintain markets for mitigation of wetlands by overseeing the banks and the trades that occurred (Corps of Engineers, 1995).

Wetland mitigation banking allows private, third-party companies to speculatively restore wetlands, which can then be sold as credits to developers who do not wish to perform their own compensatory mitigation (Figure 1). For a mitigation bank to be created and credits from that bank sold, the mitigation banker must have the site approved by a Mitigation Bank Review Team (MBRT; also referred to as the Interagency Review Team, IRT) which is made up of personnel from the Corps, EPA, and other local or federal natural resource agencies (e.g., U.S. National Marine Fisheries Service, U.S. Fish and Wildlife Service, and state departments of environmental conservation).

A key requirement of mitigation banking is that wetlands should be restored in advance of impacts (Corps of Engineers, 1995). In less-developed regions of the US, however, mitigation bankers are unlikely to speculatively invest in banks because it is doubtful that there will be sufficient demand for the created credits over time periods fro the mitigation bankers to recoup their investment. In such cases of "thin markets," development activities become hindered or slowed by the lack of available mitigation banks in a region since developers cannot easily obtain a 404 permit. Such lack of available advance credits created the impetus for in-lieu fee (ILF) programs. ILF programs are run by government or non-profit entities that collect fees from developers (in-lieu of actual compensation) and then consolidate these fees over time to build the necessary capital to restore wetlands (Environmental Law Institute [ELI], 2006; 
Wilkinson, 2009). Similar to mitigation banks, the obligation and associated liability for providing compensatory mitigation under ILF programs is transferred from the developer to the third-party mitigator. The primary difference between ILF programs and mitigation banks is the time at which mitigation occurs relative to impacts; in banking, restoration is performed prior to impacts, while ILF programs allow mitigation to be performed years after impacts are permitted (ELI 2006).

To summarize, compensatory mitigation of wetlands can now take place through three mechanisms: permittee-responsible mitigation, purchase of credits from a mitigation bank, or purchase of credits through an in-lieu fee program (ILF). These and other rules for wetlandsrelated regulation under compensatory mitigation were most recently summarized and formalized by the Corps and EPA in 2008 through the published new regulations governing compensatory mitigation, Compensatory Mitigation for Losses of Aquatic Resources (hereafter 2008 Compensatory Mitigation Rule, Corps of Engineers and EPA 2008).

\subsection{Emerging Markets for Streams}

How, when, and which wetlands merit being considered waters of the U.S. (and thus subject to federal jurisdiction via the Corps) remains highly contested between land developers and regulatory agencies, and there has been a string of mixed Supreme Court decisions over the past twenty years focused on this topic (see Downing et al., 2003). The recent Rapanos/Carabell case again raised the question of which waters in the U.S. should be considered under the regulatory authority of the Corps, and the Corps in part addressed this question through the aforementioned 2008 Compensatory Mitigation Rule. In contrast to wetlands, streams and rivers are more easily justified as 'waters of the U.S.' that can be regulated by federal power over interstate commerce. Although Section 404 of the Clean Water Act is known generally as a "wetlands rule," streams and rivers also fall under its jurisdiction, specifically as a category of “difficult to replace” type of wetland (2008 Compensatory Mitigation Rule, §332.3(e)(3)). In the past, impacts to streams were either considered by the Corps to be impractical to compensate, or compensation was performed using wetlands credits. Trading stream impacts for wetland credits is called "out of kind" compensation, since the resources traded are not of the same kind.

More recently, the Corps has begun requiring in-kind compensation for streams, thus increasing the market for stream ecosystems and stream banking separate from wetland banking. 
Additionally, because streams are a "difficult to replace resource," stream impacts must be compensated by stream restoration. This policy has created a demand for stream restoration credits, and in response, entrepreneurs have created stream mitigation banks similar to those for wetlands. Stream mitigation banking has adapted the wetland mitigation banking model to riverine systems (Lave et al., 2008), and while still relatively uncommon, stream markets have surpassed wetlands markets in the number of trades in some states, as in the case of North Carolina (described below).

\subsection{Water Quality Services}

The Clean Water Act provides for trading of credits for nitrogen $(\mathrm{N})$ and phosphorus $(\mathrm{P})$, both of which are leading sources of pollution in the U.S., particularly in the Mississippi River basin and Gulf of Mexico (Alexander et al., 2000), as well as in many Atlantic river basins, including the Chesapeake Bay, and the Albemarle-Pamlico sound of North Carolina. Under the Clean Water Act, 'point source' (PS) is distinguished from 'non-point source' (NPS) pollution: PS pollution is federally regulated under the National Pollution Discharge Elimination System (NPDES; Clean Water Act, Section 402), which is focused on discrete pollution emitters (e.g., wastewater treatment facilities), and sets discharge limits and technology standards for point sources. In contrast, NPS is regulated under total maximum daily load (TMDL) requirements, which focus on ambient water quality in watersheds. Nationally, NPS pollution, particularly from agricultural sources, comprises $76 \%$ of Nitrogen and $56 \%$ of Phosphorus reaching waterways (Ruhl et al., 2007). Although the EPA is responsible for NPDES regulation, administration of the NPDES is typically delegated to state agencies. Some states regulating NPDES have allowed water pollution trading districts to form, specifically allowing the emergence of both point source - to - point source (PS-PS) trading and point source - to - nonpoint source (PS-NPS) trading programs (see review by Woodward and Kaiser, 2003).

Under the same theory driving atmospheric emissions trading programs (Boyd et al., 2003), PS-PS trades should allow PS polluters to come into compliance more efficiently than if each polluter were required to come into compliance individually (Woodward and Kaiser, 2003). Moreover, because NPS can usually make reductions in their pollution for relatively little cost (low marginal nutrient abatement costs) than PS, PS-NPS trades should have even greater potential than PS-PS trades to achieve regulatory compliance at reduced costs. While 37 nutrient 
trading districts have been created, however, only eight have conducted any trades, and only 13 trades (one PS-NPS trade) have ever occurred to date (Ruhl et al., 2007).

Water quality trading does not initially appear to qualify as an ecosystem market since the commodity being traded is a chemical measured in pounds of $\mathrm{N}$ or $\mathrm{P}$ rather than an ecosystem service measured in ecological assessment metrics (Robertson, 2006). In the case of PS-NPS trading, NPS loads are not measured directly, as they are for PS or in air quality markets. Rather, NPS pollution reductions arise through land use changes, specifically by landowners adopting best management practices (BMPs) (e.g., riparian buffers, Robertson, 2007). Just as wetland area or stream length serve as surrogate estimates of wetland or stream ecosystem function, so land use changes through BMPs are used as surrogate estimates of water quality change. Environmental management agencies must develop ecological assessment techniques that provide conversion factors linking land use, soil type, and other variables with their impacts on water quality and nutrient (or other pollutant) loading. As a result, we can consider NPS water quality trading programs to be operating ecosystem service markets under the same definition used to articulate wetland and stream markets.

\subsection{Habitat conservation banking}

Habitat conservation banking is a recent development in ecosystem service markets. Conservation banking occurs when habitat for a recognized (listed) threatened or endangered species is impacted and offset with habitat preservation, enhancement, restoration, or creation at a different location. Conservation banking is a similar concept to wetland and stream banking, whereby compensation is performed in one location to offset similar impacts at multiple locations. The advantage of conservation banking is that the conservation bank sites are often large, contiguous, and sited more strategically (to protect habitat) than impact sites (Mead, 2008). Like wetland banking, these site advantages can produce economies of scale leading to higher quality restoration and ecological benefits not seen in small, fragmented conservation areas (Schwartz, 1999; BenDor and Brozovic 2007).

Conservation banking was first introduced in California by the U.S. Fish and Wildlife Service (FWS) to distinguish banks developed specifically for federally listed endangered species from banks designated for wetland mitigation. Unlike stream and wetland mitigation, which now is subject to explicit federal regulation, conservation banking remains regulated by a 
FWS guidance document (FWS, 2003). Although this guidance is comparable to early wetland/stream banking guidance documents, the stated goal of conservation banking is to conserve species, which can only be achieved through restoration or enhancement of the habitat needs of that specific species. Thus, while habitat conservation banks operate almost identically to wetland or stream mitigation banks, their evaluation (by a review team similar to the MBRT) is held to species-specific criteria, rather than general criteria used to evaluate wetlands and streams.

Fisheries mitigation banks are perhaps the most relevant conservation bank in the context of water markets (Cannon and Brown, 2008), although very few trades have occurred. In two cases in California, over 100 acres were restored to create the habitat specifically needed for a federally listed endangered species. This area included tidal marsh habitat primarily acquired as habitat for delta smelt, as well as Sacramento River floodplain habitat for several fish species, including Chinook salmon. In contrast to markets for wetlands, streams, and water quality, fisheries banks exhibit little market activity (trades) or research interest to date, but we expect change as more regions experiment with implementing habitat conservation banks.

\subsection{Some Regulatory Issues: Monitoring, Service areas, and In-lieu fee programs}

There are several issues with current ecosystem market regulation that require elaboration, particularly given the impacts that regulations can have on promoting successful ecological and economic outcomes. First, regulations governing all of the markets that we have described put very little emphasis on monitoring the ecological service actually being traded. In wetlands mitigation, a range of services are considered to be preserved, enhanced, and restored, including flood attenuation, nutrient retention, and wildlife habitat. The only success criteria (denoting a mitigation project 'successful') measured in most Corps districts, however, relate to hydrology (water table elevation), soil type, and vegetation type/survival (National Research Council [NRC], 2001). While these are ecological components of wetlands, it is unclear whether these components are sufficient proxies to capture the range of ecosystem services that regulations seek to protect under the auspices of the Clean Water Act.

In the case of streams in North Carolina, only physical characteristics of stream channel shape - width, slope, and riparian vegetation - are measured or restored under compensatory mitigation (Corps of Engineers, 2001). Although restoring ecological functions (e.g., species 
recovery, nutrient retention) is the stated purpose of compensatory stream mitigation, specific ecological aspects (e.g., community composition of fish or macroinvertebrates, nutrient retention) are rarely monitored as a requirement for approval of the bank to sell its credits. Evaluating the success of compensatory mitigation programs is difficult because of this disconnect between the purpose of mitigation (functional replacement) and the reality, as it is far from clear what is being achieved when just the physical habitat is being changed.

The second issue pertains to geographic 'service areas,' which is a key consideration in the economic and ecological success of an overall ecosystem market (Bonnie and Wilcove, 2008). When wetlands or streams are destroyed, regulators prefer the mitigation to be as close as possible to the impact, and if possible, within the same watershed. The reasoning for this was articulated in the first federal guidance on wetland mitigation, where regulators argued that wetlands mitigated near impacts were more likely to provide similar ecosystem services (EPA and Corps of Engineers, 1990). The area that any single mitigation bank can serve is therefore limited to the same watershed ('service area') as the impacts for which it provides compensation.

However, the scale of these 'watershed' service areas remains difficult to define explicitly, and the 2008 Compensatory Mitigation Rule has been intentionally vague on this critical issue, essentially leaving it to each District Engineer to establish and enforce the scale they consider most appropriate (see $\S 332.3(\mathrm{c})(4)$ ). If a service area is too large, then many impacts can be concentrated in one geographic area, while all of the mitigation can be geographically distant, leading to impact hot spots and localized net loss (BenDor et al., 2007). If service areas are too narrowly constrained, then there is potentially insufficient demand in any one area to justify taking on the economic risk of a speculative mitigation bank, i.e., a bank residing in a thin market. Also, Corps districts have not been consistent in defining the scale of service areas. Some districts define service areas as U.S. Geological Survey 8-digit watersheds (hydrologic unit classes [HUC]), while others define them as agglomerations of 8-digit watersheds, and still others allow trades across entire states (Wilkinson, 2009). In many areas, where local regulations augment the Corps authority, these service areas are further constrained by political boundaries such as counties (Robertson, 2006).

Issues involving service area size differ across types of ecosystem service markets: the goal of wetland and stream banking is to sustain the quality of local or receiving water bodies, 
and thus the geographic service area at the watershed scale makes intuitive and regulatory sense (NRC, 2001). In contrast, the goal of conservation banks is to preserve viable species populations (Mead, 2008). Thus, it may be entirely defensible or even preferable to allow the loss of habitat in one region in exchange for mitigation in a distant region, if the distant region is the best source of quality conservation land or genetic conservation resources. Arguably, the inadequate success to date (NRC 2001) of most ecosystem restoration suggests that there should be a balance between sites that are close but have limited restoration potential, and sites that are further away that have greater restoration potential.

A third issue regards in-lieu fee programs (Wilkinson, 2009). For traditional mitigation trading to occur, offsets (in the case of wetlands and streams this implies mitigation banks) must be at least partly established before new impacts are permitted. 'Advance' mitigation involves speculation on the part of bankers who have limited information on the future of impacts in a region or may have limited confidence in the stability of regulations that govern banking (BenDor and Brozovic, 2007). This uncertainty acts as a barrier to entry for bankers into the mitigation credit market, causing situations in which insufficient credits are available in an area to compensate for new impacts (Robertson, 2006). It is questionable whether ILF programs are ever appropriate, as they undermine both the economic and ecological original intent of mitigation banking. Ecologically, banks are meant to be established prior to impacts, thus reducing the time delay between impacts and an operational ecosystem Corps of Engineers, 1995). When using an ILF, there is an inherent time delay between impacts and establishment of a compensating ecosystem function, thus undermining an important component of ecologically responsible mitigation (BenDor, 2009).

Economically, things are even more problematic: ILF programs accept fees from developers at a rate that is assumed will be adequate to purchase and restore sites in the future. ILF programs could charge fees far in excess of restoration costs, thus holding development projects hostage. As discussed in the North Carolina case below, however, this is often not the case. ILF programs can (and often do) in fact charge insufficient fees to offset increasing property and restoration costs, which can quickly escalate beyond expectations. Moreover, ILF programs can potentially underprice private mitigation banks operating in the same areas by undercutting the market price for compensation - by collecting fees that are lower than those needed to actually build the project. Because ILF programs are stipulated to be operated by 
public agencies or non-profit groups, undercharging for ILF credits acts to subsidize aquatic resource impacts from new public and private development by charging impactors less than the full costs of compensation. That is, ILF programs can place public investments in direct competition with private enterprise.

\section{Characteristics of the North Carolina Stream and Wetlands Market}

\subsection{Policy structure in North Carolina}

In order to illustrate the operation of ecosystem service markets, we will look more closely at a case study of the evolution of markets in North Carolina, particularly focusing on policy structure and extent of market activity. Stream and wetland mitigation banking in NC is regulated by the NC Department of Environment and Natural Resources (NCDENR) and the Wilmington District of the Corps. One of the key characteristics of NC land use and environmental management has been the rapid spatial growth of several urban areas in NC. This rapid suburbanization, combined with the physiography of the state (topographically flat, humid, large wetlands throughout state), has led to significant impacts on streams and wetlands. Frequent impacts requiring permits have led to extensive demand for wetlands and stream compensatory mitigation credits.

In North Carolina, the largest impactor of aquatic resources is the North Carolina Department of Transportation (NCDOT). During the mid-1990s, NCDOT began to experience project delays due to insufficient mitigation credits produced by private bankers (EN.CITE $<$ EndNote $><$ Cite $><$ Author $>$ DyeManagementGroup $<$ /Author $><$ Year $>2007</$ Year $><$ R ecNum $>9</$ RecNum $><$ record $><$ rec-number $>9</$ rec-number $><$ reftypename="ElectronicSource" $>12</$ reftype $><$ contributors $><$ authors $><$ author $>$ DyeManagementGroup, $<$ /author $><$ /authors $><$ contribut ors $><$ titles $><$ title $>$ StudyoftheMergerofEcosystemEnhancementProgram\&amp;CleanWaterMana gementTrustFund:FinalReportofFindingsandRecommendations $</$ title $><$ titles $><$ number $>6 / 7 / 20$ $07<$ /number $><$ dates $><$ year $>2007</$ year $><$ dates $><$ urls $><$ relatedurls $><$ url $>$ http://www.nceep.net/pages/DYE_2007_EEP_CWMTF_Study_Final_Report.pdf $</$ url $></$ related-urls $><$ urls $><$ /record $></$ Cite $><$ /EndNote $>$ Dye Management Group, 2007). In response to this, the state developed the Wetland Restoration Program in 1996, re-designated as the Ecosystem Enhancement Program (EEP) in 2003. The EEP is a state-administered wetlands 
and stream mitigation program that operates as both an ILF program and mitigation bank (the history and documentation establishing the policies and practices of the EEP are summarized in Dye Management Group, 2007). The EEP was intended to use projected NCDOT construction projects as a platform from which to proactively develop mitigation credits well ahead of time in the needed geographic areas (similar to a mitigation bank). In 1998, the Corps allowed EEPgenerated mitigation credits to also be purchased by private developers, effectively opening up the market to a new type of credit consumer for which the EEP was allowed to provide compensation (under an ILF program). Thus, within North Carolina, the market for stream and wetland mitigation credits is (theoretically) made up of trades between private developers and commercial banks, trades between the NCDOT and EEP, and trades between private developers and the EEP (Figure 2). Moreover, while the EEP designs and builds some of its 'own' projects (through independent contractors), a major source of wetland and streams credits is attained through re-selling credits from "full delivery" sites - sites purchased, designed, and built by private mitigation bank firms. Thus, private mitigation banks can sell credits to private developers, or they can develop sites specifically in response to requests from the EEP.

\subsection{North Carolina ecosystem markets: economics and geography}

The NC EEP reveals some of the weakness inherent in ILF programs. Templeton et al. (2008) conducted an economic study of EEP projects for 2006 and 2007 and showed that while the EEP collected fees of $\$ 232$ per linear foot of stream mitigation, the inflation-adjusted expense for all projects was $\$ 242$ per linear foot. Moreover, this expense exceeded any inflation-adjusted mitigation fee that EEP charged in previous fiscal years. And Templeton et al. estimate that this is a conservative cost estimate as the projects are likely to still require more costs due to monitoring requirements. Given that the data set analyzed consisted of $>191,000$ linear feet of stream, the EEP may have undercharged developers by more than $\$ 1.9$ million. Again, because the EEP is an ILF program, the EEP remained responsible for providing these credits even though they did not collect adequate fees. Presumably, the state of NC provides the necessary funds to fill the gap between costs and fees collected, i.e., the state essentially provided $>\$ 1.9$ million in subsidies for environmental degradation by land developers through the EEP. 
In addition to these economic analyses, BenDor et al. (in press) recently completed an analysis of the NC stream and wetland markets and demonstrated how ecosystem markets affect the locations of ecosystem services throughout the landscape. Between 1998 and 2007, there were 839 transactions (trades) between 607 impact sites and 170 EEP compensation sites, with 431 involving regulated wetlands and 408 involving streams (49\%). Mitigation sites were spread across the state, while impact sites were concentrated in the rapidly developing urban areas (Figure 3). By specifically linking the geospatial coordinates of Corps-licensed impacts with the coordinates of EEP mitigation sites, BenDor et al. showed that mitigation transactions traded wetlands an average distance of $54.7 \mathrm{~km}$ between impact sites and mitigation (Figure 4). Also, impact sites drained, on average, $144 \mathrm{~km}^{2}$ compared to $43 \mathrm{~km}^{2}$ at mitigation sites, meaning that mitigation sites were located in streams that were, on average, smaller than streams in impacted sites.

BenDor et al. also showed that mitigation performed under the EEP led to virtually no net-loss of streams or wetlands at the 8-digit watershed scale, the broadest goal of wetlands and stream regulation. However, there were several ecologically-relevant effects: (1) defragmentation, (2) movement upstream in the watersheds, and (3) loss of place-specific functions. The first effect was a spatial defragmentation of streams and wetlands, as numerous small impacts were mitigated by fewer, large sites. While there are economies of scale for compensatory mitigation that drive the desire for large restoration sites (BenDor and Brozovic 2007), whether there are ecological advantages of single large sites over several small sites are not at all clear

(EN.CITE $<$ EndNote $><$ Cite $><$ Author $>$ Cedfeld $<<$ Author $><$ Year $>2000</$ Year $><$ RecNum $>52</$ R ecNum $><$ record $><$ rec-number $>52</$ rec-number $><$ ref-typename="JournalArticle" $>17</$ reftype $><$ contributors $><$ authors $><$ author $>$ Cedfeldt,P.T. $</$ author $><$ author $>$ M.C.Watzin $</$ author $><$ a uthor $>$ B.D.Richardson $<$ /author $><$ authors $><$ / contributors $><$ titles $><$ title $>$ UsingGIStoidentifyfun ctionallysignificantwetlandsintheNortheasternUnitedStates $</$ title $><$ secondarytitle $>$ EnvironmentalManagement $</$ secondary-title $><$ titles $><$ periodical $><$ fulltitle $>$ EnvironmentalManagement $<$ /full-title $><$ /periodical $><$ pages $>13$ $24<$ pages $><$ volume $>26<$ /volume $><$ dates $><$ year $>2000<$ year $><$ /dates $><$ urls $><$ /urls $><$ /record $><$ $/$ Cite $><$ EndNote $>$ EN.CITE $<$ EndNote $><$ Cite $><$ Author $>$ Schwartz $</$ Author $><$ Year $>1999</$ Year $><$ RecNum $>54</$ RecNum $><$ record $><$ rec-number $>54<$ /rec-number $><$ ref- 
typename="JournalArticle" $>17</$ ref-

type $><$ contributors $><$ authors $><$ author $>$ Schwartz,M.W. $<$ /author $><$ /authors $><$ contributors $><$ titl es $><$ title $>$ Choosingtheappropriatescaleofreservesforconservation $</$ title $><$ secondarytitle $>$ AnnualReviewofEcologyandSystematics $</$ secondary-title $></$ titles $><$ periodical $><$ fulltitle $>$ AnnualReviewofEcologyandSystematics $<$ /full-title $><$ periodical $><$ pages $>83$ $108<$ /pages $><$ volume $>30<$ /volume $><$ dates $><$ year $>1999$ < $<$ year $><$ /dates $><$ urls $></$ urls $><$ /record $>$ $</$ Cite $><$ /EndNote $>$ Schwartz 1999).

Second, there was a preference to restore streams and wetlands further upstream in the watershed than the impacts for which they were compensating. While this is not surprising, as smaller upstream sites are easier and cheaper to restore than large downstream sites, there will be ecological communities and functions that are both gained and lost through such market-induced pressures for upstream migration of restoration sites (Vannote et al., 1980). Third, there are place-specific functions that can be lost when impacts are mitigated by restoration sites across the landscape. For instance, when urban wetlands are destroyed and compensated by restoration in remote rural areas, there is less potential benefit for retaining stormwater runoff. Thus, there are location-specific benefits that may be particularly problematic to compensate under mitigation banking programs.

\subsection{North Carolina PS-PS and PS-NPS Market Characteristics}

The Division of Water Quality (DWQ) within the DENR is responsible for administering water quality programs and regulations in NC. Also within DENR, the Environmental Management Commission (EMC) creates water quality regulation within the Neuse River basin. This 6,192 square mile basin (Figure 5) contains a large portion of the state's population in the headwaters (Raleigh-Durham metropolitan area; a significant source of PS pollution), while agricultural areas dominate the lower watershed (corn, swine; significant sources of NPS pollution). In 1998, the Neuse River basin adopted rules requiring a reduction in $\mathrm{N}$ at the estuary to 70\% of the 1991-1995 annual average by 2001 (Hamstead and BenDor, in review). Under the rules, PS dischargers who exceed their $\mathrm{N}$ discharge allocations are required to purchase offsets from other PS emitters. The rules created an option for wastewater dischargers to meet their $\mathrm{N}$ reduction goals collectively by forming an association in which no individual members are fined as long as the group as a whole is in compliance. 
Twenty-three wastewater dischargers formed the Neuse River Compliance Association (NRCA) and the association was granted a basin-wide NPDES permit. The permit allowed the association an $\mathrm{N}$ limit equivalent to the sum of the individual limits. By 2006, the NRCA had reduced total $\mathrm{N}$ reaching the estuary by $67 \%$, far surpassing their requirements. However, to date there have been no permanent trades among members of the NRCA and only 3 temporary trades (i.e., year to year trades, or leases).

Regulators have also been concerned about the potential creation of $\mathrm{N}$ pollution hotspots because the Neuse rules only require $N$ reductions in the river's estuary (see Figure 5); there is no regulation of in-stream water quality. Over time rapidly growing urban areas will need to purchase greater $\mathrm{N}$ allotments from the agricultural areas downstream, where population is not increasing as quickly. Upstream $\mathrm{N}$ loading from urban areas, combined with a lack of in-stream water quality regulation will likely produce a water quality hotspot in the more upstream reaches of the Neuse River. While some of this nitrogen will be retained or removed from the water by natural biogeochemical processes as it is transported downstream, the levels of nitrogen that can be reached within these rivers can be quite large, with potentially toxic or biogeochemically saturating effects (Camargo and Alonso, 2006).

In addition to the NRCA, which is a PS-PS market, NC also allows PS-NPS trading. It is in this case that nitrogen trading becomes an ecosystem service market as we defined earlier. While the units of trade in the PS-NPS market are in pounds of nitrogen, NPS reductions are based on a land use classification that converts acres to pounds of nitrogen retained per year. Specifically, buffer strips are constructed on riparian lands, (Osborne and Kovacic, 1993), and the area of buffer strips is converted into pounds of nitrogen using a conversion factor. These nitrogen credits can be sold to a PS emitter as an offset. In North Carolina, to our knowledge, the first trade between private entities for PS-NPS occurred in 2008. Thus, the state of the market remains unclear. Regardless, it is worth noting that the PS-NPS market mixes the traditional environmental markets, based on pounds or volume, with markets based on complex ecological assessment techniques (ecosystem service markets).

\section{Issues on the Horizon}

\subsection{Science: Do offsets from compensatory mitigation work?}


The critical question underlying all ecosystem service markets is whether or not they work. That is, are restored ecosystems comparable to pre-development ecosystems? To date, there have been very few studies that have documented actual ecological success of stream restoration projects (Bernhardt et al., 2005), and the value and efficacy of wetland restoration continues to be questionable (NRC, 2001).

Emerging policies are placing greater emphasis on documenting real ecological change rather than relying on indicators or surrogate variables, as has been the standard approach in the past. For instance, in North Carolina, the NC Division of Water Quality in 2008 released its guidance for stream restoration via dam removal, which required substantial documentation of recovery of actual ecological functions (e.g., species, water quality), as opposed to recovery of simple channel geometry, in order to receive approval for the site from the MBRT as a compensation site. Presumably, more rigorous standards for data collection and monitoring will increase the care with which project sites are designed and (more importantly) selected. Regardless of the specific monitoring required, we expect that there will be greater emphasis on regulatory requirements for empirically-based evaluation of restoration projects in the future, thereby broadening the information available to guide future programs. Indeed, the 2008 federal compensatory mitigation rule places much greater emphasis on documenting ecological effects of restoration as a part of future compensatory mitigation practices ( $\$ 332.5$ and $\S 332.6)$.

\subsection{Policy: Geographic service areas and ILF programs}

One of the key considerations for any ecosystem service market is the size of the geographic service area that can be served by a mitigation bank (see section 2.5 above). There has been great inconsistency in the application of service areas to ecosystem markets, be they wetland, stream, or conservation banks. For streams and wetlands, the 2008 compensatory mitigation rule, while establishing a "watershed approach," leaves the scale of the market unspecified, and thus up to the interpretation and discretion of the local District Engineer. Determining a bank's service area has critically important implications for the financial viability of individual banks, as well as an ecosystem service market in general.

ILF programs represent another major policy hurdle for the private sector in future ecosystem markets. State regulators, departments of transportation, and many private developers, have argued that ILF programs are vitally necessary to prevent development 
restrictions (see preamble to the 2008 compensatory mitigation rule), and for providing compensation in geographic areas that do not generate sufficient impacts (demand) necessary for a private banker to establish a bank. ILF programs suffer from substantial problems, however, potentially leading to insufficient and unsuccessful restoration, as well as the real potential for creating artificially low or high prices (Templeton et al., 2008). These factors combine to create a system in which negative resource impacts from land development can be essentially subsidized through the provision of artificially under-priced restoration sites, as shown by the Templeton et al. (2008) study for North Carolina. Moreover, many of these ILF restoration sites are completed after impacts, in contrast to their private mitigation bank counterparts, which are required to be (at least partly) completed and certified prior to impacts. Thus, the advantages of ILF programs are, arguably, primarily for developers.

We may now be seeing a distinct shift away from ILF programs, at least in NC. Perhaps the most damning political action in NC against ILF programs came after 2008 state legislature hearings on the EEP. During these hearings, an unusual coalition of environmental groups, private restoration industry, and home builders all lobbied against the state's ILF program. The result was unanimous passage of PL 2008-152, “An act to promote compensatory mitigation by private mitigation banks." This bill stipulates that non-NCDOT impactors must use credits from private mitigation banks if those credits are available in the impacted area, and that payment to the EEP ILF Program is only acceptable if no mitigation bank credits are available. A critically important aspect of this outcome is that private mitigation banks will no longer have to compete with the EEP in providing wetland or stream credits if the mitigation banks have credits available.

Unfortunately, the NC mitigation bank act does not address the fact that many areas in the state have no private mitigation bank. Increasing the geographic service area of banks (Figure 6) is one way to provide compensatory mitigation to these areas without relying on ILF programs. Increasing the service area would provide much greater incentive for private bankers to develop their own sites, which would provide proactive restoration rather than reactive restoration, as is the case in ILF programs. In addition, larger service areas would encourage large restoration projects, as greater certainty in demand would likely lead to greater willingness to invest in larger restoration projects to take advantage of economies of scale (see Templeton et al., 2008 for analysis of economies of scale in stream restoration projects). Although we lack 
empirical evidence, our ecological understanding of other systems and processes (e.g., island biogeography theory, Schwartz, 1999), leads us to suspect that large restoration sites are ecologically superior to small ones. Finally, rather than having a discrete banking area, regulators could leverage trading ratios based on the distance away from impacts. Banks that were far away from the impacts, or in a different watershed ("low spatial quality" in Figure 6), would be given higher ratios than those that were close. Large mitigation banks would still be desirable to develop since the banker could be ensured that there would be some demand somewhere in the market for their credits.

In sum, current regulations have sought to avoid the proximity problem by implementing mitigation methods (such as ILF programs) that allow mitigation to occur after impacts. Sacrificing the benefits of advance timing of mitigation is presumably made up by the advantages of geographic proximity. In North Carolina, the stated focus of the EEP has centered on ensuring proximity of mitigation to impact sites, while ecological success criteria receive reduced emphasis, and current guidelines facilitate post-impact mitigation ("low temporal quality" in Figure 6) rather than advance mitigation. This approach represents a systemic problem with in-lieu fee programs around the United States (ELI, 2006), and has been justified by the argument that spatial proximity between impacts and mitigation sites is of paramount concern, i.e., spatial quality is preferred over temporal quality (Figure 6). This reflects recommendations that stream and wetland restoration consider "landscape position" and take a "watershed approach" as recommended by the NRC (2001). However, the EN.CITE $<$ EndNote $><$ CiteExcludeYear $=" 1 "><$ Author $>$ NRC $</$ Author $><$ Year $>2001</$ Year $><$ Re cNum $>18</$ RecNum $><$ record $><$ rec-number $>18</$ rec-number $><$ ref-typename $={ }^{\prime}$ Book $^{\prime}>6</$ reftype $><$ contributors $><$ authors $><$ author $>$ NRC $<$ /author $><$ /authors $><$ /contributors $><$ titles $><$ title $>$ CompensatingforWetlandLossesUndertheCleanWaterAct $</$ title $></$ titles $><$ dates $><$ year $>2001</$ y ear $><$ /dates $><$ pub-location $>$ Washington,D.C. $<$ publocation $><$ publisher $>$ NationalAcademyPress $<$ /publisher $><$ accession-num $>63<$ /accessionnum $><$ urls $><$ /urls $><$ /record $><$ Cite $></$ EndNote $>$ NRC (2001) review of compensatory mitigation of wetlands throughout the U.S. also noted that compensatory mitigation should preferably be established prior to permitted impacts. Determining the extent to which spatial proximity, timing, and mitigation project size affects project quality is a critical question that 
will only be answered through case studies and landscape-scale analysis of mitigation programs (Figure 6).

\subsection{Technical: Limitations to establishing property rights}

Property rights are central to environmental trading as they specify who must pay whom to modify actions relating to the environment. These rights also develop in response to changes in economic values, which stem from the development of new technology and the emergence of new markets (Demsetz, 1967). Establishing property rights for ecosystem services is particularly difficult because these services are based on ecological assessment criteria rather than direct measurements of weight or volume (even though these assessment criteria are then often used to convert into weight or volume units). Establishing property rights for ecosystem services requires sufficiently precise and accurate measurement of the quantity and quality of the service.

In $\mathrm{SO}_{2}$ emissions markets, actual $\mathrm{SO}_{2}$ is measured at the smokestack. That is, the quantity of measurement is mass, and the quality of measurement is precise to the unit being traded (tons of $\mathrm{SO}_{2}$ ). In this manner, it is like trading many other commodities for which the unit of trade is precisely known and the quality of the commodity is measured directly (e.g. gasoline, corn, hogs, nickel). In contrast to air quality markets, ecosystem service markets are plagued with uncertainty.

The initial intent of wetland trading regulation was to ensure no-net loss of the bundle of wetland ecosystem functions and services in an area. Because of the difficulty in measuring the loss or restoration of functions at individual wetland sites, particularly small sites, measures of wetland spatial extent (area) were deemed to be reasonable surrogates for function. This enshrined the use of size as the primary mechanism for seeking no-net loss in wetland mitigation. Subsequent ecosystem service markets, such as streams and endangered species habitat, have adopted similar approaches that establish functional no-net loss as a goal, but implement the regulation through size measures (e.g. length for streams, species habitat area). Thus, the currency used to commodify streams, wetlands, and habitat in ecosystem service markets is typically related to size, rather than ecologically-derived functional characteristics. 
Area can be measured precisely and quickly (some Corps requirements now require compensatory mitigation for impacts over 0.01 acres), but accurately or precisely quantifying measures of ecosystem quality is far more difficult. In a stream or wetland market, critical questions remain unanswered as to what specific functions must be present to determine that the specific site is a 'certifiable' ecosystem from which credits can be drawn. In the case of PS-NPS trading, some land area (e.g., riparian buffer) is converted from acres into pounds of nitrogen. A crucial yet unresolved issue is whether the farmer's actions of installing a buffer strip actually produce a measurable reduction in nitrogen loads downstream, or is the conversion of land itself sufficient to generate water quality credits. How should water quality improvements be verified? How changes in ecological quality of traded ecosystems pushes the extent to which regulators choose to monitor actions and enforce precise property rights. While monitoring specific ecological functions has received increasing recognition in new regulations (see 2008 federal compensatory mitigation rule, $§ 332.5)$, it remains an on-going area of study for researchers (NRC, 2001).

\subsection{Economic Issues: Un-bundling, un-stacking, and double-dipping}

One of the critical issues, or opportunities, in the function of ecosystem markets is the potential for 'credit stacking'-- selling separate services furnished by the same ecosystem in separate markets. For instance, 100 acres of a wetland bank are first sold as wetland mitigation units, and then sold again as water quality credits, endangered species credits, or even carbon credits.

Credit stacking has also been called 'unbundling', or 'double-dipping,' although there are several distinctions between these three concepts. Unbundling is the overarching concept that ecosystem processes and functions can be separated: a wetland can be designated specifically for nitrogen retention, rather than the bundle of ecosystem services that constitute the traditional unit of trade of wetland or stream mitigation credits. Credit stacking specifically involves acquiring credits for a single acre of property that can be independently sold in multiple ecosystem markets. Double-dipping is similar to stacking, except that credits are understood to 'double up' natural resource benefits.

The distinction between stacking and double-dipping is unclear. Fox (2008) argues that part of the distinction pertains to the additional activities that are necessary to gain the additional 
credits. For example, if 200 acres of riparian buffer are established specifically to sell as endangered species habitat credits, but are then sold additionally into a market for NPS water quality credits, then Fox argues that the banker would be guilty of double-dipping, because the water quality credits were established separately on the same land with no additional land management activities. To circumvent double dipping, Fox argues that the natural resource value accounting must be careful and precise; it must clearly separate the riparian buffer needed for water quality provision and that needed for salamander habitat provision, thereby allowing these two areas to be sold separately. The current precision and accuracy of ecosystem service accounting, however, is exceedingly low, thereby causing potential barriers to establishing such closely co-existing ecosystem service markets. If regulators decide that double-dipping is undesirable, then they would need to somehow limit certification of new bank credits (for new markets) to those that are generated by additional land improvements that would not have otherwise been achieved without proactive measures (Fox 2008).

There are additional ecological and regulatory arguments against credit stacking. Robertson and Mikota (2007) have argued that ecosystem functions do not stack and un-stack like Lego blocks, but rather are interrelated and intertwined. One example is nitrogen trading, where the only pathway to permanent removal of nitrogen from water involves denitrification, the conversion of nitrate $\left(\mathrm{NO}_{3}\right)$ into gaseous nitrogen $\left(\mathrm{N}_{2}\right)$. The biogeochemical process of denitrification is limited by the availability of carbon (Alexander et al., 2000), thus inextricably linking carbon to nitrogen markets. Even at the most simple biochemical level, nitrogen and phosphorus are intertwined through basic stoichiometry, making separate water quality markets for these different nutrients scientifically nonsensical. Moving into more complex ecological interactions, such as the species interactions and food webs that are inherent to conservation banks, will undoubtedly be substantially more complex. In the end, unbundling ecosystems is a highly problematic scientific concept.

From a regulatory standpoint, it is clear that it is difficult to 'un-stack' ecosystem services derived from ecological restoration projects. There are multiple agencies that regulate ecosystem features and ecosystem service markets: the Corps regulates streams and wetlands via the Clean Water Act, while the U.S. Fish and Wildlife Service regulates conservation habitat banks through the Endangered Species Act (Mead, 2008) and private organizations oversee carbon trading (Fox, 2008). Credit un-stacking poses a substantial administrative hurdle for any 
banker who wishes to engage multiple agencies simultaneously. At the most basic level, unbundling or un-stacking credits makes unclear what actually changes hands when credits are sold (Robertson, 2007).

When a wetland or stream credit is sold for compensatory mitigation, the banker has 1) inevitably sold a permanent easement to that property, ensuring that the physical property will stay in its wetland/stream natural condition, and 2) performed certain management actions that will ensure the viability of the wetland or stream into the future. The transaction, however, has occurred to fulfill the legal requirements of section 404(b) of the Clean Water Act. In the case of un-stacking that same property into water quality credits or endangered species credits, or even carbon credits, the sale of these credits would be to fulfill a completely separate regulatory requirement, such as the Endangered Species Act. Quite simply, the legal status for unstacking, unbundling, and double-dipping is unclear, and will likely only be clarified by a series of court decisions that pit some environmental regulations against others.

\subsection{Markets: Unintended Consequences}

Additional issues emerge in ecosystem service markets from the non-intuitive interactions between ecosystem and market processes. To date, we have insufficient data from which to derive empirical observations about landscape scale ecosystem market behavior, but there are a few modeling studies which provide some additional insight.

In the case of streams, Doyle and Yates (in review), linked an economic model of freeentry equilibria with a simple ecological model in order to examine the interactions of stream markets and ecological processes in programs aimed at preventing resource net-losses. Their modeling showed that when implementing a no-net loss program, a regulator must not only account for the ecological differences between restored and natural ecosystems, but also consider the effect of market entry on the number and size of restoration projects. They showed that in a system with little to no restoration scale economies, the number of entrants into an ecosystem service market will be greater than the number that maximizes welfare. The effect of this excess entry on restored ecosystems is to encourage the restoration of smaller sites rather than larger sites, which are generally considered less ecologically desirable than larger sites. Thus, considerations of joint processes are crucial when designing and evaluating such programs. A similar conclusion was reached for a different type of ecosystem market by Armsworth et al. 
(2006), who examined habitat conservation banks within a system that included real estate property market dynamics. They showed that interaction between the local market for land and conservation purchases could actually lead to a decrease in overall biodiversity. Conservation purchases can affect land prices and potentially displace development toward biologically valuable areas or accelerate the pace of development.

While limited in number, emerging studies that link ecological processes and characteristics with economic models suggest that these coupled ecological-economic systems can produce unintended, or at least non-intuitive, consequences. A critical need at this point in time is to more fully explore these types of coupled systems.

\section{Conclusions}

Within freshwater ecosystems, ecosystem service markets now span wetlands, streams, nonpoint source water quality, and habitat conservation. Most importantly, the regulatory framework for these markets is very unstable, with major policy changes being the norm rather than the exception (Robertson, 2006). Moreover, under the auspices of compensatory mitigation, the science and economics of ecological restoration is also in its infancy.

There are state and federal policies that can, if structured incorrectly, undermine some of the original intents of compensatory mitigation programs (e.g., in-lieu fee programs). There are other policies that can make private provision of compensatory mitigation difficult (e.g., small geographic service areas). Resolving these tensions between the policies developed for specific problems that emerge locally and the initial goals of broad, federal environmental policy will inevitably remain an on-going problem inherent to this type of adaptive management. So long as scientific monitoring can play a role in evaluating the programmatic success for maintaining and restoring the integrity of the nation's waters, then we expect that ecosystem service markets can play an important role in freshwater ecological restoration.

\section{Acknowledgments}

Initial funding for this work was provided by the UNC Institute for the Environment.

\section{Abbreviations used in text:}

Corps: Army Corps of Engineers

DWQ: Division of Water Quality 
EEP: Ecosystem Enhancement Program

EMC: Environmental Management Commission

EPA: Environmental Protection Agency

FWS: Fish and Wildlife Service

ILF: In lieu fee program

IRT: Interagency Review Team

MBRT: Mitigation Bank Review Team

MEA: Millennium Ecosystem Assessment

NCDENR: North Carolina Department of Environment and Natural Resources

NCDOT: North Carolina Department of Transportation

NPDES: National Pollution Discharge Elimination System

NPS: non-point source

NRC: National Research Council

NRCA: Neuse River Compliance Association

PS: Point-source

TMDL: Total Maximum Daily Load

WRP: Wetland Restoration Program

\section{References}

Alexander, R.B., R.A. Smith, and G.E. Schwaz, 2000. Effect of stream channel size on the delivery of nitrogen to the Gulf of Mexico. Nature 403: 758-761.

Armsworth, P.R., G.C. Daily, P. Kareiva, and J.N. Sanchirico, 2006. Land market feedbacks can undermine biodiversity conservation. Proceedings of the National Academy of Sciences 103: 5403-5408.

BenDor, T., 2009. A dynamic analysis of the wetland mitigation process and its effects on no net loss policy. Landscape and Urban Planning 89: 17-27.

BenDor, T.K., N. Brozovic, and V.G. Pallathucheril, 2007. Assessing the socioeconomic impacts of wetland mitigation in the Chicago Region. Journal of the American Planning Association 73: 263-282.

BenDor, T., and N. Brozovic, 2007. Determinants of spatial and temporal patterns in compensatory wetland mitigation banking. Environmental Management 40: 349-364. 
BenDor, T., J. Sholtes, and M.W. Doyle, in press. Landscape characteristics of a stream and wetland mitigation banking program. Ecological Applications.

Bernhardt, E.S., M.A. Palmer, J.D.Allan, G.Alexander, K. Barnas, S. Brooks, J. Carr, S. Clayton, C. Dahm, J. Follstad-Shah, D. Galat, S. Gloss, P. Goodwin, D. Hart, B. Hassett, R. Jenkinson, S.Katz, G.M.Kondolf, P. S. Lake, R. Lave, J. L.Meyer, T.K. O’Don, 2005. Synthesizing U.S. River Restoration Efforts, Science 308: 636-637

Bonnie, R., and D.S. Wilcove, 2008. Ecological considerations. Conservation and Biodiversity Banking, N. Carroll, J. Fox, and R. Bayon (eds), Earthscan, London, pp 53-67.

Boyd, J., D. Burtraw, A. Kurpnick, V. McConnell, R.G. Newell, K. Palmer, and J.N. Sanchirico, 2003. Trading cases. Environmental Science and Technology 217.

Camargo, J.A., and A. Alonso, 2006. Ecological and toxicological effects of inorganic nitrogen pollution in aquatic ecosystems. A global assessment. Environment International 32: 831-849. Cannon, T., and H. Brown, 2008. Fish banking. Conservation and Biodiversity Banking, N. Carroll, J. Fox, and R. Bayon (eds), Earthscan, London, pp 159-170.

Corps of Engineers, 1995. Federal Guidance for the Establishment, use and operation of mitigation banks. Federal Register 60(228):58605-58614.

Corps of Engineers and Environmental Protection Agency [EPA], 2008. Compensatory Mitigation for Losses of Aquatic Resources: Final Rule. Federal Register 73(70):19594-19705. Corps of Engineers, 2001. Stream Mitigation Guidelines for North Carolina. Corps of Engineers - Wilmington District, NC Department of Environment and Natural Resources, NC Division of Water Quality, and Environmental Protection Agency. Wilmington, NC.

Daily, G.C., S. Alexander, P.R. Ehrlich, L. Goulder, J. Lubchenco, P.A. Matson, H.A. Mooney, S. Postel, S.H. Schneider, D. Tilman, G.M. Woodwell, 1997. Ecosystem Services: Benefits supplied to human societies by natural ecosystems. Issues in Ecology, 2: Spring.

Demsetz, H., 1967. Toward a theory of property rights. American Economic Review 57: 347359.

Downing, D.M., C. Winer, and L.D. Wood, 2003. Navigating through Clean Water Act jurisdiction: a legal review. Wetlands 23: 475-493.

Doyle, M.W. and A. Yates, in review. Ecosystem service markets under no-net-loss regulation. Water Resources Research. 
Dye Management Group, 2007. Study of the Merger of Ecosystem Enhancement Program and Clean Water Management Trust Fund. Final Report to the North Carolina General Assembly, Raleigh, NC.

Environmental Law Institute [ELI], 2006. The Status and Character of In-Lieu Fee Mitigation in the United States. Environmental Law Institute, Washington, DC.

EPA [Environmental Protection Agency] and Corps of Engineers, 1990. Memorandum of Agreement Between the EPA and the Department of Army concerning the determination of mitigation under the Clean Water Act Section 404(b)(1) Guidelines.

Fox, J., 2008. Getting two for one: opportunities and challenges in credit stacking. Conservation and Biodiversity Banking, N. Carroll, J. Fox, and R. Bayon (eds), Earthscan, London, pp 171180.

Hamstead, Z.A., and T. BenDor, in review. Nutrient trading for enhanced water quality: A case study of North Carolina's Neuse River Compliance Association. Environment and Planning. Hough, P., and M.M. Robertson, in press. Mitigation under section 404 of the Clean Water Act: where it comes from, what it means. Wetland Ecology and Management.

King, D.M., and L.W. Herbert, 1997. The fungibility of wetlands. National Wetlands Newsletter Sept: 10-13.

Lave, R., M.M. Robertson, and M.W. Doyle, 2008. Why you should pay attention to stream mitigation banking. Ecological Restoration 26: 287-289.

Mead, D.L., 2008. History and theory: The origin and evolution of conservation banking. Conservation and Biodiversity Banking, N. Carroll, J. Fox, and R. Bayon (eds), Earthscan, London, pp. 9-31.

Millennium Ecosystem Assessment [MEA], 2005. Ecosystems and Human Well-Being: Synthesis. Washington, DC: Island Press.

National Resources Council [NRC], 2001. Compensating for Wetland Losses Under the Clean Water Act. National Academy Press, Washington DC.

Osborne, L.L., and D.A. Kovacic, 1993. Riparian vegetated buffer strips in water quality restoration and stream management. Freshwater Biology 29: 243-258.

Robertson, M.M., 2006. Emerging markets in ecosystem services: Trends in a decade of entrepreneurial wetland banking. Frontiers in Ecology and the Environment 6: 297-302. 
Robertson, M.M., 2007. Discovering price in all the wrong places: commodity definition and price under neoliberal environmental policy. Antipode 39: 500-526.

Robertson, M.M., and M. Mikota, 2007. Water quality trading and wetland mitigation banking: different problems, different paths? National Wetlands Newsletter 29: 10-15.

Ruhl, J.B., S.E. Kraft, and C.L. Lant, 2007. The Law and Policy of Ecosystem Services. Island Press, Washington, DC.

Schwartz, M.W., 1999. Choosing the appropriate scale of reserves for conservation. Annual Review of Ecology and Systematics 20: 83-108.

Templeton, S.R., C.F. Dumas and W.T. Sessions, 2008. Estimation and analysis of expenses of design-bid-build projects for stream mitigation in North Carolina. Research Report RR08-01, Department of Applied Economics and Statistics, Clemson University. USFWS (U.S. Fish and Wildlife Service). 2003. Guidance for the establishment, use and operation of conservation banks. USFWS, Washington, D.C.

Vannote, R.L., G.W. Minshall, K.W. Cummins, J.R. Sedess, and C.E. Cushing, 1980. The river continuum concept. Canadian Journal of Fisheries and Aquatic Science 37: 130-137.

Vitousek, P.M., H.A. Mooney, J. Lubchenco, and J.M. Melillo, 1997. Human domination of Earth's ecosystems. Science 277: 494-499.

Wilkinson, J., 2009. In-lieu fee mitigation: coming into compliance with the new Compensatory Mitigation Rule. Wetlands Ecology and Management, doi:10.1007.s11273-008-9120-8.

Woodward, R.T., and R.A. Kaiser, 2003. Market structures for US water quality trading. Review of Agricultural Economics 24: 366 


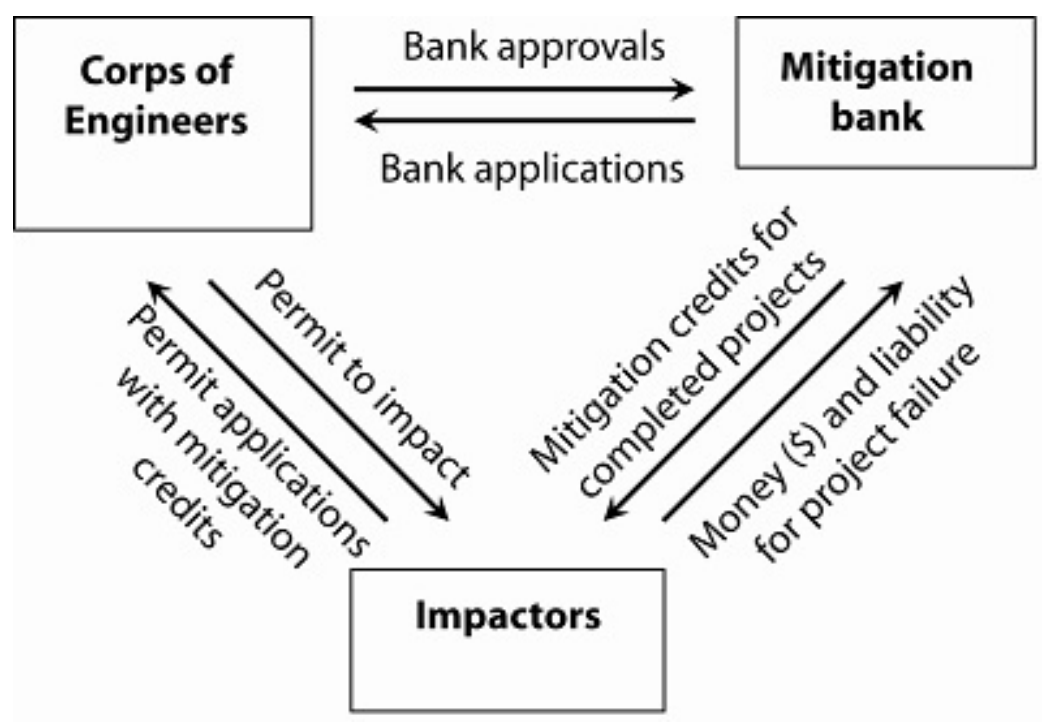

Figure 1. Relationships between agencies, impactors (developers), and mitigation bankers in the originally conceived structure of compensatory mitigation banking. Note that once impactors have purchased compensatory mitigation credits, the liability for mitigation site failure is transferred from the impactor to the mitigation bank. 


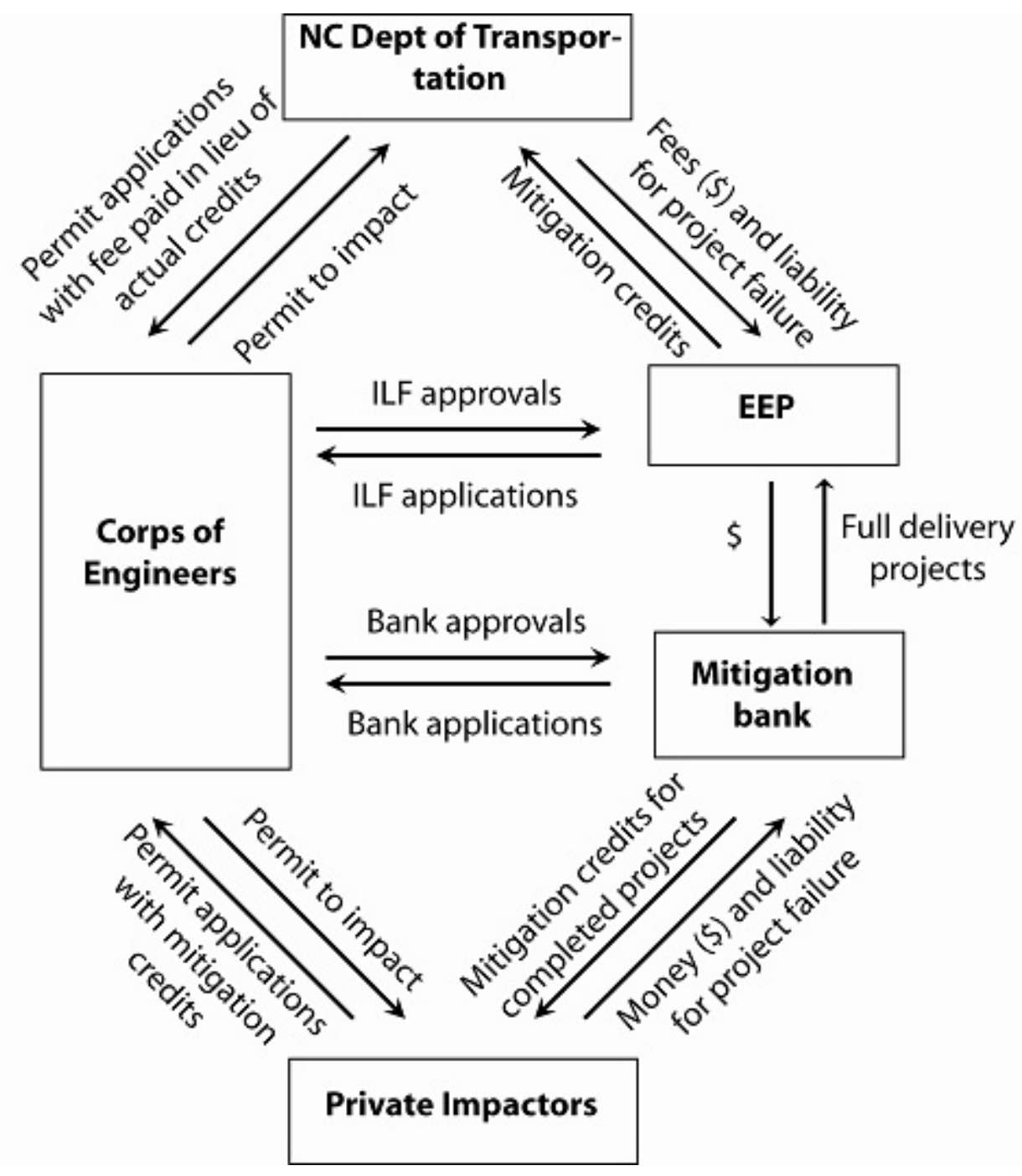


Figure 2. Relationships between agencies, impactors, and mitigation bankers in North Carolina in the presence of the Ecosystem Enhancement Program. Note that private impactors can also pay a fee in lieu of mitigation credits via the EEP, even though that is not shown on the figure. 


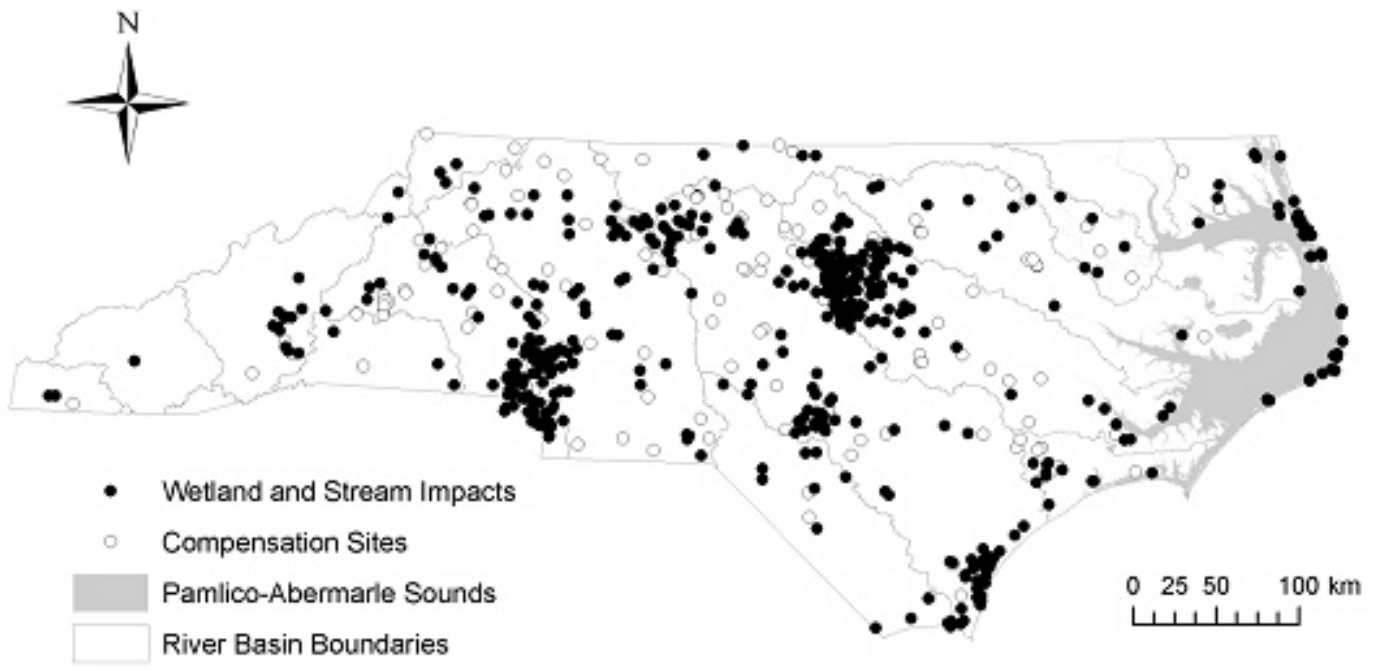

Figure 3. Impact and mitigation sites under the auspices of the EEP in North Carolina (adapted from BenDor et al., in press). 


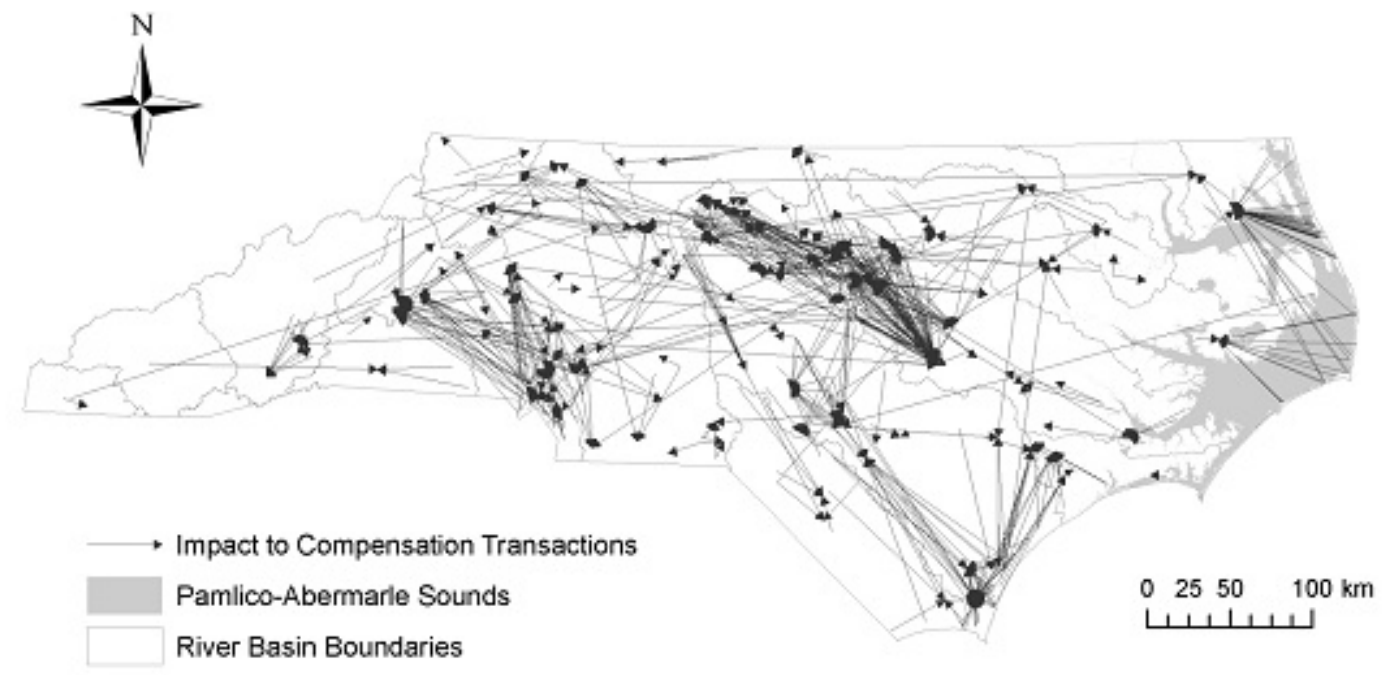

Figure 4. Map of EEP compensatory mitigation transactions in North Carolina. Each arrow maps compensatory mitigation transactions, originating at a stream or wetland impact site and terminating at the compensatory mitigation site (adapted from BenDor et al., in press). 


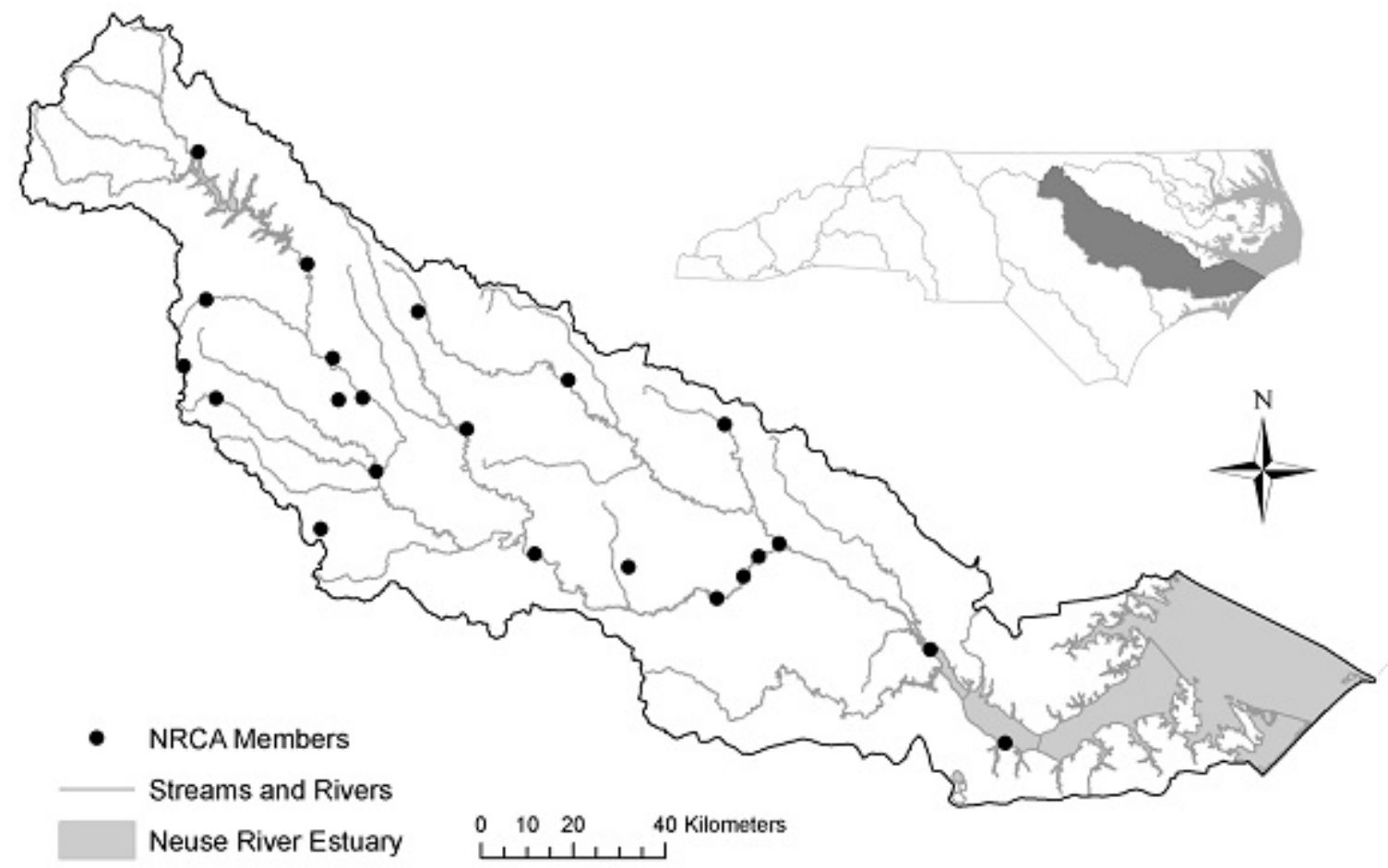

Figure 5. Neuse River Compliance Association Map. NRCA members are wastewater treatment plant operators who, as a group, must comply with nitrogen reduction targets. 


\section{Trade-offs in Compensatory Mitigation}

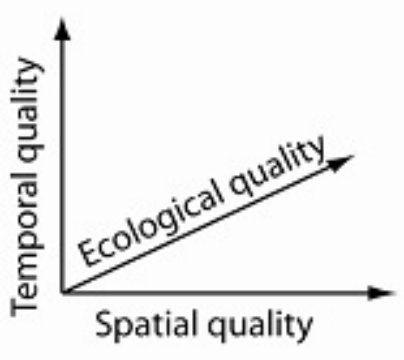

Ideal case: all characteristics of restoration project are high indicating a site close to impacts, restoration completed prior to impacts, with demonstrable ecological benefits

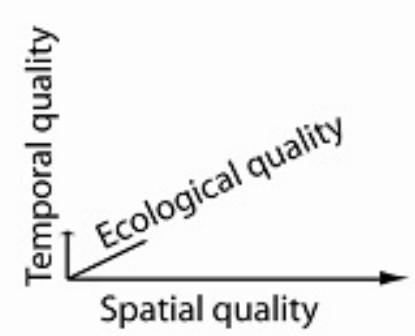

Near site: typical project to date; located in relatively close proximity; restoration not completed at time of impacts; only minimal indicator data collected to show success of project

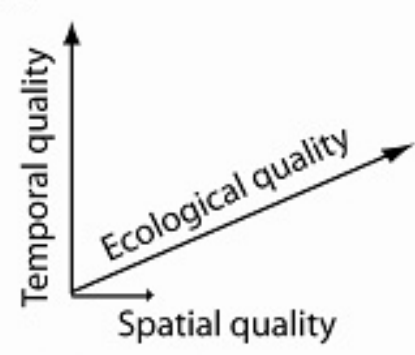

Far-large site: large site with demonstrated ecological benefits beyond surrogate metrics alone; completed prior to impacts including rigorous data for monitoring; located further away from impact site

Temporal quality: timing of restoration and monitoring relative to impacts; high temporal quality indicates that restoration and monintoring completed in advance of impacts; low temporal qulaity associated with restoration completed after impacts Spatial quality: location of restoration relative to impacts; high spatial quality associated with restoration site in close proximity and landscape position to impacts; low spatial quality associated with distant mitigation site, or out of watershed Ecological quality: amount of demonstrable physical, biological, and chemical benefits at restoration site; High ecological quality associated with actual measurements of functional changes (e.g., community composition, nutrient retention, sediment load reductions); low ecological quality associated with no direct monitoring or reliance on surrogate variables

Figure 6. Conceptual model of tradeoffs in compensatory mitigation programs between spatial proximity, timing, and quality of restoration (from BenDor et al., in press). 